\section{Cycle of abuse in young adolescents}

\section{DeAr Sirs}

Child psychiatrists working in child guidance clinics provide assessments and therapy for abused children through the team-workers in their clinics. But for the past year or more I have noticed that adolescents referred for inappropriate sexualised behaviour or aggressive behaviour have disclosed abuse of physical, verbal and sexual kind.

\section{Cases}

(a) A 14-year-old girl looking older than her age was referred for aggression and abuse towards her younger brother and parents for about 16 months. There was no history of mental illness within the family but the girl felt deprived and neglected because of her parents' busy life-style. She showed lack of interest in schooling and running away behaviour. She was associating with older peers and disclosed she has been raped three times in past six months and also had received abusive treatment over longer period from older peers in the community.

(b) A 16-year-old boy was referred for self-destruction, overdose, abuse to family members and very aggressive attitude. His parents have split up since sister disclosed a year ago that father has sexually abused her. The boy also disclosed that father had abused him and he had received bullying, rough treatment and some physical abuse from his peers.

(c) A 15-year-old girl living with father and stepmother started behaving oddly with aggression, spitefulness towards younger half sib, and rudeness towards parents for over a 10 month period. She gave a history of general abuse and sexual harassments for over 18 months.

(d) A 14-year-old girl from a broken home started behaving badly since her liaison with much older boyfriends. Aggression, running away and abuse towards herself were associated with poor quality relationships and work at school. Apart from inappropriate treatment from older people in the community she also showed evidence of physical abuse by father at home.

The above cases were referred to a clinic specifically for abusive and/or sexualised behaviour and where in the assessment stages they had disclosed abuse from others. There are many other cases where abuse has contributed to their symptomatology of being abused.

The relationship between abusive and sexualised behaviour to probable physical/sexual abuse received by younger children needs to be examined further. The abused may become the abuser and the cycle continues.

Child and Family Guidance Clinic

J. Katwala

Thundersley, Benfleet,

Essex SS7 $3 A T$

See page 39.

\section{More psychiatric casualties of the ambulance dispute}

\section{DeAr SIRS}

I read with interest Dr Jones' report (Psychiatric Bulletin, July 1990) in which he drew attention to a psychiatric casuality of the ambulance dispute.

It would be fair to say that many psychiatric patients are dependent on a network of services to maintain their life in the community. The elderly mentally infirm in particular have long been recognised as being especially vulnerable when any part of their support system breaks down; an apparently minor event can be the trigger for the collapse of the whole network and thus can precipitate hospital admission. In the Day Hospital for the Elderly in a deprived London borough in which I work, we assessed the effect of the ambulance strike on our elderly psychiatrically ill patients and their relatives. Many of our patients are too frail to be able to attend for day care without ambulance transport so the strike effectively meant that they stayed at home.

Forty-three mentally infirm were attending for day care between one and three days per week at the onset of the strike. A minority of these patients were able to attend by other forms of transport, irregularly, throughout the dispute.

Three patients with functional illness relapsed, two with depression and one with schizophrenia. They had all become very anxious about being unable to attend the Day Hospital and related their decline to this. The depressed patients both required admission; the schizophrenic patient was managed with home visits and frequent reviews.

Four other functionally ill patients showed deterioration in their mental states but were supported through domiciliary visits. Of the demented, nine caused significant concern because of the resultant stress on relatives when the patients could not attend. Two of these patients were admitted to long stay beds during the strike and one shortly after, purely because their relatives could not adequately cope without day care. They might still be living at home were it not for the dispute.

The 16 patients cited were our particular casualties of the ambulance strike; these patients received little news coverage in comparison to some of the more acutely ill users of the service. However, the effect of the strike on these patients and their relatives has been profound and far reaching; the cost of lengthy in-patient stays and permanent long term care is the price that the health service has had to pay.

Margaret Scott Day Hospital

Kim Davidson

Appleby Road, London E16; and

Medical College of St Bartholomew's Hospital

West Smithfield, London ECI 
Reference

JONES, G. H. (1990) A casualty of the ambulance dispute. Psychiatric Bulletin, 14, 402.

\section{How to get in touch with patients in a developing country}

\section{DeAR SIRS}

When establishing a new psychiatric service, the early priorities are to obtain adequate buildings, to ensure supplies of medication and to train staff. Any spare time that a psychiatrist may have for treating patients is likely to be occupied by a middle class clientele. The next stage, exemplified by Dr Sidandi's (1990) description of a provincial service in Zimbabwe, is to get community treatment going. How should psychiatrists set about contacting patients? Persuading traditional healers to refer on suitable patients is a favoured method in Africa but is not possible everywhere.

An account is given here of my 1972 experience of holding out-patient clinics in rural areas of Dominica which may still be of interest as it was then virgin territory from a psychiatric point of view. There was a small, mainly custodial, unit for acutely disturbed patients run by nurses. There had been occasional visits to the island by psychiatrists employed by development agencies but there had been no regular community psychiatric service. The situation is now much improved thanks to the subsequent work of a Dominican psychiatrist, Dr John Royer.

Dominica is a West Indian island with a population at that time of about 70,000 , half of whom lived in the capital and the rest in scattered rural communities. Although small, it is so mountainous that travel between one part of the island and another was difficult. I held regular out-patient clinics in three rural areas separated from each other by at least an hour's drive. Each area had a cottage hospital, at which a district medical officer was based and a health centre staffed by between two and four district nurses. The latter had mostly been through the training programme run by the island's main hospital, which included little on psychiatry.

In one of the areas (Portsmouth) information was spread by hospital staff by word of mouth and patients were allowed to refer themselves to my clinic at the cottage hospital. In a second (Grand Bay) patients were referred by district nurses. In a third (Marigot) patients were initially referred by the district medical officer to a cottage hospital clinic but this appeared less successful than the method used in Grand Bay so a switch was made to district nurse referrals.

It may be seen from the Table that the doctor referred clinic was the least satisfactory as few patients complied with follow-up and the proportion of severely ill people seen was quite low. The doctor, although himself Dominican, was a recent arrival from another part of the island. Self referrals were often appropriate, but compliance with follow-up was again a problem. The best results were provided by district nurse referral, the two separate areas proving very similar.

This experience served to re-emphasise two truisms: first that psychiatrists are likely to get the best results if they work with people who may be

TABLE

\begin{tabular}{lccccc}
\hline & $\begin{array}{c}\text { Number of } \\
\text { new patients }\end{array}$ & $\begin{array}{c}\text { \% not } \\
\text { psychiatrically } \\
\text { ill }\end{array}$ & $\begin{array}{c}\% \text { mildly } \\
\text { ill }\end{array}$ & $\begin{array}{c}\% \text { asked to } \\
\text { reverely for } \\
\text { ill* }\end{array}$ & $\begin{array}{c}\text { follow-up } \\
\text { who failed } \\
\text { to do so }\end{array}$ \\
\hline $\begin{array}{c}\text { Portsmouth (self referrals) } \\
\text { Grand Bay (district } \\
\text { nurse referred) }\end{array}$ & $145^{* *}$ & 25 & 59 & 16 & 41 \\
$\begin{array}{c}\text { Marigot Hospital } \\
\text { (doctor referred) }\end{array}$ & 81 & 19 & 56 & 25 & 29 \\
$\begin{array}{c}\text { Marigot Health Centre } \\
\text { (district nurse referred) }\end{array}$ & 24 & 12 & 71 & 17 & 65 \\
\hline
\end{tabular}

*The criterion for 'severely ill' was that the patient might have been considered to require intensive day or in-patient treatment had this been available.

**The population of the Portsmouth area was greater than that of the other two. Accurate figures were not available, but it is likely that the proportion of patients seen per head of population was similar in each area and in the range 2-5 per hundred. 